BIOMEDICAL AND BIOSOCIAL ANTHROPOLOGY
$\begin{gathered}\text { Official Journal of the International Academy } \\ \text { of Integrative Anthropology } \\ \text { journal homepage: http://bba-journal.com }\end{gathered}$

\title{
Peculiarities of relationships of characteristics of adaptation capabilities of the organism and indicators of motor activity of students
}

\author{
Serheta I. V., Drezhenkova I. L., Panchuk O. Yu., Bandurka N. M., Dmitriev M. O.
}

National Pirogov Memorial Medical University, Vinnytsya, Ukraine

\section{ARTICLE INFO}

Received: 28 September 2020

Accepted: 26 October 2020

UDC: $613: 159.946 .2: 378.4$

\section{CORRESPONDING AUTHOR}

e-mail: serheta@gmail.com Serheta I. V.
The health of student youth is largely determined by the level of functional capabilities of the organism, which depends on the level of motor activity, that is the total number of movements that a person performs in a given period of time. The purpose of the work is to establish the features of the relationship between the characteristics of adaptive capacity, functional status and level of development of psychophysiological functions and criteria for motor activity of students. The research was conducted on the basis of National Pirogov Memorial Medical University, where 385 students (200 young girls and 185 young boys) were supervised, who, taking into account the peculiarities of the distribution of different levels of motor activity, were divided into 3 comparison groups - with potentially low, medium and potentially high levels of motor activity. The values of daily energy consumption, number of locomotions and duration of the dynamic component in the daily budget were used as the leading criteria of hygienic assessment of students' motor activity. Functional features and adaptive capabilities of the organism were determined using conventional methods. The analysis of the obtained results involved the use of a standard application package of multidimensional statistical analysis "Statistica 6.1 for Windows". The results of studies conducted on the basis of correlation analysis procedures indicate the fact that the largest number of correlations between the characteristics of psychophysiological functions and the leading characteristics of health and indicators of academic performance in professionally oriented disciplines studied are recorded in girls, and boys who belonged to the group with an average level of physical activity (daily energy expenditure of 9000-11000 kJ in young girls and $11000-13500 \mathrm{~kJ}$ in young boys). The use of cluster analysis procedures during the prognostic assessment of indicators of health and academic performance in professionally-oriented disciplines, made it possible to identify 3 clusters of the studied characteristics of the functional state of students, which have the most pronounced effect on their values: visual-motor speed cluster (indicators of the latent period of simple and differentiated visual-motor response), visual-sensory cluster (indicators of critical fusion of light flickers and efficiency of work performed) and integrativecoordination cluster (a number of indicators that reflect the properties of major nervous processes, characteristics coordination of movements, indicators of attention functions, etc.). Using factor analysis procedures, it determined that both young girls and young boys have the most positive impact on academic performance in vocational disciplines such factors as "functional state of the visual sensory system", "functional state of coordination" and "functional state of higher nervous activity".

Key words: students, motor activity, functional state of organism, adaptation capabilities, peculiarities of relationships.

\section{Introduction}

The issues of preserving the health of student youth, improving the adaptive and functional capabilities of girls and boys who study are among the most pressing issues of theoretical and preventive medicine that need to be addressed [13, 15, 20].

In this context, it should be noted that the processes of 
gradual deterioration in the performance of students of modern higher education institutions, which are registered, raise these issues to one of the key places in the structure of unresolved issues and determine the comprehensive development of such areas of hygiene for children, adolescents and young people as university medicine in general and university hygiene in particular $[3,8,13]$.

Numerous recent scientific studies have shown that the health of student youth is largely determined by the level of functional capabilities of the body, which, in turn, depends on the level of motor activity, ie the total number of movements that a person performs for a single time interval (minute, hour, day, week). Therefore, the criterion indicators of motor activity of children, adolescents and youth are motor activity during educational and work activities, motor activity in the process of physical education, motor activity in free time, etc. [5, 6, 14, 17, 18].

However, it should be noted that in contrast to the physiological and hygienic regulation of motor activity of student youth, which have been the subject of a number of scientific studies conducted in recent decades, the physiological and hygienic regulation of motor activity of student youth is almost not studied, although and the conditional classification of the factors influencing processes of formation of habitual motor activity is defined. As favorable factors determine a healthy lifestyle, optimal alternation of work and rest, physical and mental work, a rational daily routine, a variety of means of physical education and more. Instead, among the unfavorable factors include educational overload, neglect of physical culture, unfavorable psychological climate, the presence of bad habits [1, 4, 7, 14, 17, 22, 23].

However, so far not fully formed idea of the basics of students' health on the basis of physiological and hygienic features of motor activity, not studied features of normal motor activity of modern students studying in higher medical education, not studied features of psychophysiological functions of the body and processes of formation of characteristics of mental and physical working capacity of students which differ in features of the organization of motor activity, etc.

The purpose of the work is to establish the features of the relationship between the characteristics of adaptive capacity, functional status and level of development of psychophysiological functions and criteria for motor activity of students.

\section{Materials and methods}

Comprehensive research was conducted on the basis of National Pirogov Memorial Medical University, Vinnytsya. 385 students (including 200 young girls and 185 young boys) were supervised in the dynamics of the 6-year period, which, taking into account the peculiarities of the distribution of different levels of motor activity, were divided into 3 comparison groups - respectively into groups with potentially low (1 group of motor activity - values of daily energy consumption up to $9000 \mathrm{~kJ}$ in young girls and up to $11000 \mathrm{~kJ}$ in young boys), average (2 group of physical activity - values of daily energy consumption from 9000 to 11000 $\mathrm{kJ}$ in young girls and 11000 to $13500 \mathrm{~kJ}$ in young boys) and potentially high (3 group of motor activity - values of daily energy expenditure over $11000 \mathrm{~kJ}$ in young girls and over $13500 \mathrm{~kJ}$ in young boys) levels of motor activity.

The values of daily energy consumption, number of locomotions and duration of the dynamic component in the daily budget of time were used as the leading criteria of hygienic assessment of students' motor activity. The values of daily energy consumption $(\mathrm{kJ})$ were calculated by applying the time-table method. The number of locomotions in the daily cycle (steps) was determined based on the use of standard digital pedometers SIGETA PMT-01, I-PDM 2002 new та Pedometr G014. The duration of the dynamic component in the daily budget of time (minutes) was estimated by timing the main types of daily educational and extracurricular activities [15, 17].

Functional features of higher nervous activity were evaluated on the basis of determining the values of latent periods of simple and differentiated visual-motor response, indicators of mobility and balance of nervous processes using chronoreflexometry, functional characteristics of the visual sensory system and somatosensory analyzer were investigated by estimating the values of the critical frequency of light flicker on the basis of the technique "Svitlotest" and coordination of movements by tremometry, stability of attention and mental performance were studied using Schulte tables and based on the use of proofreading [9, $14,16,17,19]$.

Indicators of morbidity with temporary disability and chronic morbidity and the results of subjective assessment of students' own health were used as criterion indicators of the state of health and adaptive capacity of the organism. At the same time, academic performance indicators were determined on the basis of copying data on annual and intermediate student performance, as well as in accordance with the results of final tests in individual disciplines with their subsequent analysis [9, 14, 16, 19].

The obtained data were subjected to statistical processing using the application package of multidimensional statistical analysis "Statistica 6.1" (licensed № BXXR901E245722FA) based on the application of procedures of descriptive statistics, correlation, cluster and factor analysis.

\section{Results}

Analyzing the results obtained during the application of correlation analysis procedures, it should be noted that the indicators of health and adaptive capacity of the body, typical for young girls of the 1st group of motor activity (daily energy consumption up to $9000 \mathrm{~kJ}$ ), were determined to have a close correlation with the characteristics of the level of development of such psychophysiological functions as the magnitude of the latent period of a simple visual-motor 
reaction $(r=0.34, p<0.05)$, mental endurance $(r=0.35$, $p<0.05)$, the critical frequency of light flicker $(r=-0.28, p<0.05)$ and the integrated indicator of coordination of movements $(r=0.27, p<0.05)$, however, indicators of the level of academic success in professionally-oriented disciplines to be determined were marked by the presence of close correlations with the latent period of differentiated visualmotor reaction $(r=0.37, p<0.05)$, mental endurance $(r=0.39$, $p<0.05)$, critical frequency of light flicker $(r=-0.54, p<0.01)$ and bones of touch during tremometry $(r=0.27, p<0.05)$.

At the same time, the indicators of health and adaptive capacity of the body, inherent in young boys of group 1 motor activity (daily energy expenditure up to $11000 \mathrm{~kJ}$ ), which were determined, had a close correlation with the characteristics of the level of development of psychophysiological functions such as balance nervous processes $(r=0.39 p<0.05)$, the degree of involvement in the activities performed $(r=0.37, p<0.05)$, and mental endurance $(r=0.34, p<0.05)$, at the same time, indicators of the level of academic performance in professionallyoriented disciplines to be determined, were characterized by strong correlations with the critical frequency of light fusion flicker $(r=-0.43, p<0.05)$ and the integral indicator of coordination of movements during tremometry $(r=0.32$, $\mathrm{p}<0.05)$.

During the assessment of the relationship between health indicators and adaptive capacity of the body, inherent in girls 2 groups of motor activity (daily energy expenditure from 9000 to $11000 \mathrm{~kJ}$ ), a close correlation was established between the studied values and the characteristics of the level of development such psychophysiological functions as the magnitude of the latent period of a simple visualmotor reaction $(r=0.44, p<0.01)$ and differentiated visualmotor reaction $(r=0.33, p<0.05)$, balance $(r=0.41, p<0.001)$ and mobility $(r=0.31, p<0.05)$ of nervous processes and the number of touches during tremometry $(r=0.28, p<0.05)$, at the same time, indicators of the level of academic success in professionally oriented disciplines, which were determined, were characterized by strong correlations with the values of the latent period of simple visual-motor reaction $(r=0.53, p<0.001)$ and differentiated visual-motor reaction $(r=0.49, p<0.001),(r=0.38, p<0.01)$ and mobility $(r=0.29, p<0.05)$ nervous processes, the critical frequency of light flicker $(r=-0.41, p<0.05)$ and the number of touches during tremometry $(r=0.30, p<0.05)$.

However, indicators of health and adaptive capacity of the body, inherent to young people of 2 group of motor activity (daily energy expenditure from $11000 \mathrm{~kJ}$ to 13500 $\mathrm{kJ}$ ), which were determined, had a close correlation with the characteristics of the level of development of psychophysiological functions such as the magnitude of the latent simple visual-motor reaction $(r=0.68, p<0.001)$ and differentiated visual-motor reaction $(r=0.46, p<0.001)$, balance $(r=0.42, p<0.001)$ and mobility $(r=0.36, p<0.05)$ of nervous processes, the critical frequency of light flicker ( $r=-$ $0.36, p<0.05$ ) and the number of touches during tremometry $(r=0.38, p<0.01)$, at the same time, indicators of the level of academic success in professionally-oriented disciplines to be determined were characterized by the presence of strong correlations with the values of the latent period of simple visual-motor reaction $(r=0.47, p<0.001)$ and differentiated visual-motor reaction $(r=0.46, p<0.001)$, balance $(r=0.38, p<0.01)$ and mobility $(r=0.29, p<0.05)$ of nervous processes and the number of touches during tremometry $(r=0.32, p<0.05)$, ie a much larger number was registered there are correlations than in the previous case.

Finally, during the research it should be noted that the indicators of health and adaptive capacity of the body, inherent in girls 3 groups of physical activity (daily energy expenditure above $11000 \mathrm{~kJ}$ ), which were determined, were closely correlated with the characteristics of the level of development such psychophysiological functions as the values of the latent period of differentiated visual-motor response $(r=0.34, p<0.05)$ and data on the number of touches $(r=0.31, p<0.05)$ and the values of the integrated index of coordination of movements $(r=0.35, p<0.05)$ during tremometry, however, indicators of academic performance in professionally oriented disciplines were subject to determination, were characterized by the presence of strong correlations with the balance of nervous processes $(r=0.37, p<0,05)$, as well as indicators of the number of touches $(r=0.34, p<0.05)$ and the values of the integrated index of coordination of movements during tremometry $(r=0.29, p<0.05)$.

At the same time, the indicators of health and adaptive capacity of the body, inherent in young men of the 3rd group of motor activity (daily energy expenditure over $11000 \mathrm{~kJ}$ ), which were determined, had a close correlation with the data of the correlates of psychophysiological functions both for the number of touches $(r=0.30, p<0.05)$ and the values of the integrated indicator of coordination of movements $(r=0.32, p<0.05)$ during tremometry, at the same time, indicators of the level of academic success in professionally oriented disciplines were characterized by strong correlations with the values of critical fusion $(r=-0.35, p<0.05)$ and integrated coordination of movements during tremometry $(r=0.35, p<0.05)$. Thus, it was among the representatives of this group of students that the lowest number of correlations was observed between such important from the adaptively significant point of view indicators as leading characteristics of health status and indicators of academic success in professionally oriented disciplines and a number of subjects' indicators of psychophysiological functions.

During the use of cluster analysis procedures for both young girls and young boys group 1 of physical activity (daily energy consumption up to $9000 \mathrm{~kJ}$ in young girls and up to $11000 \mathrm{~kJ}$ in young boys) and in the case of determining the leading characteristics of health, and in the case of prognostic assessment of the level of academic performance in professionally-oriented disciplines, the presence of 3 leading clusters of psychophysiological 
functions should be considered inherent, namely: visualmotor speed cluster (cluster № 1), visual-sensory cluster (cluster № 2) and integrative-coordination cluster ( cluster № 3). The visual-motor speed cluster should include indicators of the latent period of simple and differentiated visual-motor response, the visual-sensory cluster indicators of the critical frequency of light flicker fusion and the efficiency of work performed, the integrative-coordination cluster - a number of indicators that reflect as properties of the main nervous processes, accurate in their content characteristics of coordination of movements, especially the number of touches during tremometry and an integrated indicator of coordination of movements, as well as a number of characteristics of attention functions such as degree of involvement in mental activity and mental endurance, and the last cluster was the closest to the characteristics of health and academic performance, which were studied in the multidimensional space of the measured indicators.

The situation was similar for both students of the 2 nd group of physical activity (the level of daily energy expenditure from 9000 to $11000 \mathrm{~kJ}$ for young girls and from $11000 \mathrm{~kJ}$ to $13500 \mathrm{~kJ}$ for young boys). During the research, both during the determination of the leading characteristics of health and during the prognostic assessment of academic performance in professionally-oriented disciplines, the following clusters of psychophysiological functions should also be considered a priority: visual-motor speed cluster (cluster № 1), visual-sensory cluster (cluster № 2), integrative-coordination cluster (cluster № 3). These included indicators of the latent period of simple and differentiated visual-motor response (cluster № 1), indicators of critical fusion of light flicker and efficiency of work performed (cluster № 2), a number of indicators that reflect the properties of the main nervous processes, accurate in terms of content characteristics of coordination of movements, especially the number of touches during tremometry and an integral indicator of coordination of movements, as well as a number of characteristics of attention functions, such as the degree of involvement in activities and mental endurance (cluster № 3) and as in the previous case, the last cluster was the closest to the characteristics of health and academic performance in the multidimensional space of indicators measured.

Finally, the relationship between the leading characteristics of health status and the characteristics of the level of academic performance in professionally oriented disciplines and psychophysiological functions of students of the 3rd group of motor activity (daily energy expenditure over $11000 \mathrm{~kJ}$ in young girls and over13500 kJ in young boys) was quite similar to the previous two cases. And in this case the most significant should be considered visual-motor speed cluster (cluster № 1), visual-sensory cluster (cluster № 2), integrative-coordination cluster (cluster № 3). The visual-motor speed cluster included indicators of the latent period of simple and differentiated visual-motor response, the visual-sensory cluster included indicators of the critical frequency of light flicker fusion and the efficiency of work performed, the integrative coordination cluster included a number of indicators. reflecting as properties of the main nervous processes, accurate in their content characteristics of coordination of movements, especially the number of touches during tremometry and an integral indicator of coordination of movements, as well as a number of characteristics of attention functions such as degree of involvement and mental endurance. The latter cluster, in this case as well, was closest to the characteristics of health and academic performance that were studied in the multidimensional space of the measured indicators.

According to the data of factor analysis procedures among students belonging to 1 group of motor activity, features of interdependence of characteristics of level of educational success on professionally-oriented disciplines (y) and indicators of development of psychophysiological functions of young girls and young boys should be defined and formalized in the form relationships (1-2):

in young girls of 1 group of motor activity:

$y=0.391 f_{1}+0.135 f_{2}+0.438 f_{3}$;

where the factor $f_{1}$ - should be defined as the "functional state of the visual sensory system" (the share of variance $32.68 \%$ ) and is associated with the critical frequency of fusion of light flickers of female students; factor $f_{2}$ - should be defined as a "functional state of coordination of movements" (the share of variance - $21.71 \%$ ) and, above all, includes in its structure indicators that provide information about the features of such leading characteristics of coordination abilities of the studied girls as indicators of the number of touches tremometry and the value of the integrated indicator of coordination of movements; factor $f_{3}$ - should be defined as a "functional state of higher nervous activity" (the share of variance $22.38 \%$ ) and, above all, combines in its structure indicators of the latent period of differentiated visual-motor response and balance of nervous processes in young girls;

in young boys of 1 group of motor activity:

$y=0.3121 f_{1}+0.194 f_{2}+0.505 f_{3}$

where the factor $f_{1}$ - should be defined as the "functional state of the visual sensory system" (the share of variance $33.59 \%$ ) and is associated with the critical frequency of fusion of light flickers of students; factor $f_{2}$ - should be defined as the "functional state of coordination of movements" (the proportion of variance - $26.95 \%$ ) and combines in its structure the characteristics of the body's coordination abilities, namely: indicators of the number of touches during tremometry, test speed and magnitude integrated indicator of coordination of movements; factor $f_{3}$ - should be defined as a "functional state of higher nervous activity" (the proportion of variance - $24.50 \%$ ) and, above all, includes in its structure indicators of the latent period of simple and differentiated visual-motor response of young boys. 
Peculiarities of interdependence between the characteristics of the level of academic success in professionally-oriented disciplines $(y)$ and indicators of development of psychophysiological functions of the body among students belonging to 2 groups of motor activity, it was necessary to present and formalize in the form of relationships (3-4):

in young girls of 2 group of motor activity:

$y=0.324 f_{1}+0.212 f_{2}+0.428 f_{3}$;

where the factor $f_{1}$ - should be defined as a "functional state of higher nervous activity" (the share of variance $32.20 \%$ ) and, above all, combines in its structure indicators of the latent period of simple and differentiated visual-motor response of girls; factor $f_{2}$ - should be defined as the "functional state of the visual sensory system" (the share of variance $-25.87 \%$ ) and is associated with the critical frequency of fusion of light flickers of female students; factor $\mathrm{f}_{3}$ - should be defined as "functional state of coordination of movements" (dispersion share - $22.89 \%$ ) and, first of all, includes in its structure indicators that provide information about the features of such leading characteristics of coordination abilities of the studied young girls as indicators of the number of touches tremometry and the value of the integrated indicator of coordination of movements;

in young boys of 2 group of motor activity:

$y=0,388 f_{1}+0,395 f_{2}+0,237 f_{3}$;

where the factor $f_{1}$ - should be defined as "functional state of higher nervous activity" (the share of variance -31.83 $\%$ ) and, above all, includes in its structure indicators of the latent period of simple and differentiated visual-motor response of adolescents, factor $f_{2}$ - should be defined as functional the state of the visual sensory system "(share of variance $-23.87 \%$ ) and is related to the indicators of the critical frequency of merging of light flickers of students; factor $\mathrm{f}_{3}$ - should be defined as the "functional state of coordination of movements" (the share of variance - $27.02 \%$ ) and combines in its structure the characteristics of coordination abilities, namely: indicators of the number of touches during tremometry, test speed and the value of the integral movement coordination indicator;

Peculiarities of the interdependence between the characteristics of the level of academic success in professionally-oriented disciplines $(y)$ and indicators of development of psychophysiological functions of the body among students belonging to 3 groups of motor activity, had to be defined and formalized in the form of relationships (5-6):

in young girls of 3 group of motor activity:

$y_{2}=0.190 f_{1}+0.352 f_{2}+0.348 f_{3}$;

where the factor $f_{1}$ - should be defined as the "functional state of coordination of movements" (the share of variance - $28.08 \%$ ) and, above all, includes in its structure indicators that provide information about the characteristics of such leading characteristics of coordination abilities of the studied young girls, as indicators of the number of touches during tremometry and the value of the integrated indicator of coordination of movements; factor $\mathrm{f}_{2}$ - should be defined as "functional state of the visual sensory system" (dispersion share $-27.49 \%$ ) and is related to the critical frequency of fusion of light flickers of female students; factor $\mathrm{f}_{3}$ - should be defined as a "functional state of higher nervous activity" (the share of variance $-22.01 \%$ ) and, above all, combines in its structure indicators of the latent period of simple and differentiated visual-motor response of young girls;

in young boys of 3 group of motor activity:

$y=0.373 f_{1}+0.240 f_{2}+0.338 f_{3} ; \quad$ (6)

where the factor $f_{1}$ - should be defined as the "functional state of coordination of movements" (the proportion of variance $-31.00 \%$ ), which is determined by the values of the number of touches during the tremometry; factor $f_{2}$ should be defined as the "functional state of the visual sensory system" (the share of variance - $28.67 \%$ ) and is related to the critical frequency of fusion of light flickers of students; factor $\mathrm{f}_{3}$ - should be defined as a "functional state of higher nervous activity" (the share of variance $-21.59 \%$ ) and, above all, includes in its structure indicators of the latent period of simple and differentiated visual-motor response of young boys.

\section{Discussion}

The initial component of prognostic research in any field of preventive medicine should be considered the use of correlation analysis procedures, the main content of which is to establish the relationship of the studied indicators both among themselves and with a number of criteria that have a certain interpretation of phenomena, which are observed and analyzed according to the values of the correlation coefficient and the characteristics of the degree of its significance [2, 8, 10, 11, 12, 14, 16, 19, 21].

The use of correlation analysis procedures in the studies showed that the largest number of correlations between the characteristics of psychophysiological functions and the leading characteristics of health and indicators of academic performance in vocational disciplines studied were recorded in girls and in boys who belonged to 2 groups of physical activity (level of daily energy expenditure from 9000 to $11000 \mathrm{~kJ}$ in young girls and from $11000 \mathrm{~kJ}$ to $13500 \mathrm{~kJ}$ in young boys), which according to existing ideas confirms the most pronounced positive impact on the processes of their development and formation of such organization of motor activity. The lowest number of correlations was characteristic of students of the 3rd group of physical activity (daily energy expenditure level over $11000 \mathrm{~kJ}$ in young girls and more than $13500 \mathrm{~kJ}$ in young boys), indicators of students belonging to the 1st motor activity group (daily energy consumption level up to $9000 \mathrm{~kJ}$ in young girls and up to $11000 \mathrm{~kJ}$ in young boys), occupied an intermediate position.

The application of agglomeration-hierarchical methods of cluster analysis, the main purpose of which is to 
determine the patterns of grouping of individual objects of study taking into account their leading features by combining into separate local sets, ie into separate clusters in the multidimensional space of the studied features, provided an opportunity to (based on finding the minimum distance between the individual indicators that are closest and combining them into a single cluster and giving it a common index, as well as calculating the distances from the formed clusters to other units of homogeneous groups) identify 3 leading clusters that have a positive impact on processes of formation of both criterion characteristics of the state of health, and indicators of the level of academic success in professionally-oriented disciplines [2, 8, 11, 14, 16, 19, 21].

Adequately, based on the subject and objectives of the study, the use of cluster analysis procedures both in the prognostic assessment of leading indicators of health and in determining the level of academic success in professionally-oriented disciplines, provided an opportunity to identify 3 leading clusters of functional characteristics the body of students who had the most pronounced effect on their values, namely: visual-motor speed cluster (indicators of the latent period of simple and differentiated visual-motor response), visual-sensory cluster (indicators of the critical frequency of light flicker and work efficiency) and integrative-coordination cluster (a number of indicators that reflect both the properties of the main nervous processes, accurate in their content characteristics of coordination of movements, especially the number of touches during tremometry and the value of the integrated indicator of coordination of movements, and a number of characteristics tic of attention functions, such as the degree of involvement in the activity performed and mental endurance), which was actually the closest to the characteristics of health and academic performance in the multidimensional space of the measured indicators.

Another method of establishing the interdependence of indicators that determine the functional state and adaptive capacity of the body of young girls and young boys, which are characterized by different approaches to the organization of motor activity and, consequently, different values of motor activity in the context of their impact on the state of the studied indicators. is a factor analysis, the main procedures of which provide an opportunity to perform a quantitative analysis of directly non-measurable indicators that can be assessed by studying certain features, and, therefore, allow a correct description of multidimensional objects with redundant output characteristics based on deep, system-forming in their content, the processes of formation of their indicators $[2,8,11,14,16,19]$.

Using factor analysis procedures, it was determined that both young girls and young boys have the most positive impact on academic performance in vocational disciplines such factors as "functional state of the visual sensory system", "functional state of coordination" and "functional state of higher nervous activity". However, the share of their variance in the overall structure of factor loads differs significantly: among students whose daily energy consumption does not exceed $9000 \mathrm{~kJ}$ (young girls) and $11000 \mathrm{~kJ}$ (young boys), the most significant contribution is inherent in such a factor as the "functional state of the visual sensory system", which is primarily related to the critical frequency of light flashes fusion of students (young girls have a share of dispersion of $32.68 \%$, young boys respectively $33.59 \%$ ), among students whose daily energy consumption ranges from 9000 to $11000 \mathrm{~kJ}$ (young girls) and from 11000 to $13500 \mathrm{~kJ}$ (young boys), - for such a factor as "functional state of higher nervous activity" (young girls have a share of variance of $32.20 \%$, young boys respectively $31.83 \%$ ), among students whose daily energy expenditure exceeds $11000 \mathrm{~kJ}$ (young girls) and $13500 \mathrm{~kJ}$ (young boys), - for such a factor as "functional state of coordination of movements" (in young girls the share of variance is $32.20 \%$, respectively, in young boys - respectively $31.83 \%)$.

Given the peculiarities of the processes of professional development of future medical professionals associated with the need to assimilate large amounts of theoretically and practically significant information, this situation indicates in favor of clear signs of positive effects of motor mode, characteristic of students, the value of daily energy expenditure range from 9000 to $11000 \mathrm{~kJ}$ and from 11000 to $13500 \mathrm{~kJ}$, respectively, which contributes to the predominant development of the leading functional characteristics of higher nervous activity of studying young girls and young boys.

\section{Conclusions}

1. The results of research conducted on the basis of correlation analysis procedures show the fact that the largest number of correlations between the characteristics of psychophysiological functions and the leading characteristics of health and indicators of academic performance in professionally oriented disciplines studied, is registered in both young girls and young boys, who belong to the 2 nd group of physical activity (the level of daily energy expenditure from 9000 to $11000 \mathrm{~kJ}$ in young girls and from $11000 \mathrm{~kJ}$ to $13500 \mathrm{~kJ}$ in young boys).

2. The use of cluster analysis procedures both during the prognostic assessment of leading indicators of health, and when determining the level of academic success in professionally-oriented disciplines, provides an opportunity to identify 3 leading clusters of studied characteristics of the functional state of students who perform the most pronounced influence on their values, namely: visual-motor speed cluster (indicators of latent period of simple and differentiated visual-motor reaction), visual-sensory cluster (indicators of critical frequency of flickering of light and efficiency of work performed) and integrative-coordination cluster (a number of indicators that reflected as properties of the main nervous processes, characteristics of coordination of movements, indicators of attention functions, etc.), which is closest to the characteristics of health and 
academic performance.

3. When using factor analysis procedures, it was determined that among both young girls and young boys the most positive impact on academic performance in professional-oriented disciplines are factors such as "functional state of the visual sensory system", "functional state of coordination" and "functional state of higher nervous activity".

4. Given the peculiarities of the processes of professional development of future medical professionals, which is associated with the need to assimilate large

\section{References}

[1] Ahn, S., \& Fedewa, A. L. (2011). A meta-analysis of the relationship between children's physical activity and mental health. Journal of Pediatric Psychology, 36(4), 385-397. doi: 10.1093/jpepsy/jsq107

[2] Antomonov, M. lu. (2017) Математическая обработка и анализ медико-биологических данных [Mathematical processing and analysis of biomedical data]. Киев: МИЦ "Мединформ" - Kiev: MIC " Medinform ".

[3] Bailey, R. (2006). Physical education and sport in schools: A review of benefits and outcomes. Journal of School Health, 76(8), 397-401. doi: 10.1111/j.1746-1561.2006.00132.x

[4] Biddle, S. J., \& Asare, M. (2011). Physical activity and mental health in children and adolescents: A review of reviews. British Journal of Sports Medicine, 45(11), 886-895. doi: 10.1136/ bjsports-2011-090185

[5] de la Haye, K., Robins, G., Mohr, P., \& Wilson, C. (2011). How physical activity shapes, and is shaped by, adolescent friendships. Social Science and Medicine, 73(5), 719-728. doi: 10.1016/j.socscimed.2011.06.023

[6] Ferrer-Caja, E., \& Weiss, M. R. (2000). Predictors of intrinsic motivation among adolescent students in physical education. Research Quarterly for Exercise and Sport, 71(3), 267-279. doi: 10.1080/02701367.2000.10608907

[7] Houwen, S., Hartman, E., \& Visscher, C. (2009). Physical activity and motor skills in children with and without visual impairments. Medicine and Science in Sports and Exercise, 41(1), 103. doi: 10.1249/MSS.0b013e318183389d

[8] Moroz, V. M., Makarov, S. Yu., Serebrennikova, O. A., \& Serheta, I. V. (2020). Навчальний стрес та психофізіологічні критерії оцінки адаптаційних можливостей організму студентів закладів вищої медичної освіти [Educational stress and psychophysiological criteria for assessing the adaptive capacity of the body of students of higher medical education]. Вінниця : ТОВ "TВОРИ" - Vinnytsya: TOV "TVORY".

[9] Raigorodskii, D. Ya. (2011). Практическая психодиагностика. Методики и тесты [Practical psychodiagnostics. Techniques and tests]. Самара: Издательский дом "Бахpax-M" - Samara: Publishing house "Bakhrakh-M".

[10] Raudsepp, L., \& P?II, P. (2006). The relationship between fundamental motor skills and outside-school physical activity of elementary school children. Pediatric Exercise Science, 18(4), 426-435. doi: 10.1123/pes.18.4.426

[11] Rebrova, O. Yu. (2006). Статистический анализ медицинских данных. Применение пакета прикладных программ Statistica [Statistical analysis of medical data. Application of the Statistica software package]. Москва: МедиаСфера - Moscow: MediaSphere.

[12] Reed, J., Metzker, A., \& Phillips, D. (2004). Relationships between physical activity and motor skills in middle school children. amounts of theoretically and practically significant information, the data indicate in favor of clear signs of positive influence of motor mode inherent in students, the value daily energy consumption ranges from 9000 to $11000 \mathrm{~kJ}$ and from 11000 to $13500 \mathrm{~kJ}$, respectively, which contributes to the predominant development of the leading functional characteristics of higher nervous activity of young girls and young boys and requires further consideration and analysis from the standpoint of determining its structural and dynamic characteristics in weekly, monthly and annual cycles.

Perceptual and Motor Skills, 99(2), 483. doi: 10.2466/ pms.99.2.483-494

[13] Serdiuk, A. M., Polka, N. S., \& Serheta, I. V. (2012). Псuхогuгиена детей и подростков, страдающих хроническими соматическими заболеваниями [Psychohygiene of children and adolescents suffering from chronic somatic diseases]. Вінниця: Нова книга - Vinnytsya: Nova knyha.

[14] Serheta, I. V., Bardov, V. H., Drezhenkova, I. L., \& Panchuk, O. Yu., (2020). Гігієнічні нормативи рухової активності студентів закладів вищої медичної освіти та шляхи її опmимізації [Hygienic standards of motor activity of students of higher medical education institutions and ways of its optimization]. Вінниця : ТОВ "ТВОРИ" - Vinnytsya: TOV "TVORY".

[15] Serheta, I. V., Panchuk, O. Yu., Stoian, N. V., Drezhenkova, I. L., \& Makarov, S. Yu. (2016). Університетська гігієна у контексті імплементації "Закону про вищу освіту": фізіологогігієнічні основи, реалії та шляхи розвитку [University hygiene in the context of the implementation of the "Law on Higher Education": physiological and hygienic foundations, realities and ways of development]. Довкілля та здоров'я Environment and health, 4(80), 46-52.

[16] Serheta, I. V., Panchuk, O. Yu., \& Yavorovskyi, O. P. (2020). Гігієнічна діагностика професійної придатності студентів закладів медичної освіти (на прикладі стоматологічних спеціальностей) [Hygienic diagnostics of professional suitability of students of medical education institutions (on the example of dental specialties)]. Вінниця : TOB "TВOРИ" - Vinnytsya: TOV "TVORY".

[17] Sukharev, A. G. (1991). Здоровье и физическое воспитание детей и подростков [Health and physical education of children and adolescents]. Москва: Медицина - Moscow: Medicine.

[18] Thomas, N., \& Williams, D. (2008). Inflammatory factors, physical activity, and physical fitness in young people. Scandinavian Journal of Medicine \& Science in Sports, 18(5), 543-556. doi: 10.1111/j.1600-0838.2008.00824.x

[19] Tymoshchuk, O. V., Polka, N. S., \& Serheta, I. V. (2020). Hayкові основи комплексної гігієнічної оцінки якості життя та адаптаційних можливостей сучасної учнівської і студентської молоді [Scientific bases of complex hygienic assessment of quality of life and adaptive possibilities of modern pupil and student youth]. Вінниця : ТОВ "ТВОРИ" Vinnytsya: TOV "TVORY".

[20] World Health Organization. (2013). Young people's health - a challenge for society. Report of a study group on young people and health for all by the year 2000. World Health Organization.

[21] Wrotniak, B. H., Epstein, L. H., Dorn, J. M., Jones, K. E., \& Kondilis, V. A. (2006). The relationship between motor 
proficiency and physical activity in children. Pediatrics, 118(6), 1758-1765. doi: 10.1542/peds.2006-0742

[22] Zeng, Q., Dong, S. Y., Sun, X. N., Xie, J., \& Cui, Y. (2012). Percent body fat is a better predictor of cardiovascular risk factors than body mass index. Brazilian Journal of Medical and Biological Research, 45(7), 591-600. doi: 10.1590/S0100-

\section{X2012007500059}

[23] Ziviani, J., Poulsen, A., \& Hansen, C. (2009). Movement skills proficiency and physical activity: A case for Engaging and Coaching for Health (EACH)-child. Australian Occupational Therapy Journal, 56(4), 259-265. doi: 10.1111/j.14401630.2008.00758.x 